\title{
Virtual Anatomy: The Dissecting Theatre of the Future-Implementation of Cinematic Rendering in a Large 8 K High-Resolution Projection Environment
}

\author{
Franz A. Fellner ${ }^{1,2}$, Klaus Engel ${ }^{3}$, Christoph Kremer ${ }^{4}$ \\ ${ }^{1}$ Central Radiology Institute, Kepler University Hospital, Medical Faculty of the Johannes Kepler University, Linz, \\ Austria; ${ }^{2}$ Medical Faculty of the Friedrich-Alexander-University Erlangen-Nürnberg, Erlangen, Germany; ${ }^{3}$ Siemens \\ Healthineers, Erlangen, Germany; ${ }^{4}$ Ars Electronica Center, Linz, Austria
}

Correspondence to: Franz A. Fellner, Franz.fellner@kepleruniklinikum.at

Keywords: Virtual Anatomy, Education, Cinematic Rendering (CR), Volume Rendering (VR), High-Resolution, 3D Display, Computed Tomography (CT), Magnetic Resonance (MR)

Received: June 19, 2017 Accepted: July 24, $2017 \quad$ Published: July 27, 2017

Copyright $\odot 2017$ by authors and Scientific Research Publishing Inc.

This work is licensed under the Creative Commons Attribution International License (CC BY 4.0).

http://creativecommons.org/licenses/by/4.0/

(c) (i) Open Access

\section{ABSTRACT}

Modern computer techniques have been in use for several years to generate three-dimensional visualizations of human anatomy. Very good 3-D computer models of the human body are now available and used routinely in anatomy instruction. These techniques are subsumed under the heading "virtual anatomy" to distinguish them from the conventional study of anatomy entailing cadavers and anatomy textbooks. Moreover, other imaging procedures (X-ray, angiography, CT and $M R$ ) are also used in virtual anatomy instruction. A recently introduced three-dimensional post-processing technique named Cinematic Rendering now makes it possible to use the output of routine CT and MR examinations as the basis for highly photo-realistic 3-D depictions of human anatomy. We have installed Cinematic Rendering (enabled for stereoscopy) in a high-definition 8K 3-D projection space that accommodates an audience of 150 . The space's projection surface measures $16 \times 9$ meters; images can be projected on both the front wall and the floor. A game controller can be used to operate Cinematic Rendering software so that it can generate interactive real-time depictions of human anatomy on the basis of CT and MR data sets. This prototype installation was implemented without technical problems; in day-to-day, real-world use over a period of 22 months, there were no impairments of service due to software crashes or other technical problems. We are already employing this installation routinely for educational offerings open to the public, courses for students in the health professions, and (continuing) professional education units for medical interns, residents and specialists-in, so to speak, the dissecting theater of the future. 


\section{INTRODUCTION}

We recently introduced a new way of post-processing images from radiological examinations such as computed tomography (CT) and magnetic resonance (MR). Cinematic Rendering is the first such technique that makes it possible to produce highly photo-realistic three-dimensional visualizations of the human body [1]. The depictions generated by Cinematic Rendering come across as extremely realistic because this method, in contradistinction to previous 3-D post-processing techniques, takes into account the complex interactions of photons with human anatomy [1-6].

Since the application of imaging procedures is by no means limited to medical fields (for example, the use of CT in, among other areas, industrial material analysis \& testing), corresponding 3-D post-processing methods, in addition to their medical applications [1-8], also come into consideration for such tasks as non-destructive analyses in archeology [9].

In another project, we have been visualizing CT and MR data sets in 2-D and interactive 3-D realtime graphics (until July 2015 by means of a volume rendering program created in house) in a high-resolution $8 \mathrm{~K}$ projection space featuring a 16-by-9-meter projection surface-Deep Space at the Ars Electronica Center.

There, we have succeeded in implementing Cinematic Rendering with 3-D stereoscopy and in carrying out real-time rendering of CT and MR data sets [10]. This development yields an innovative possibility to employ virtual anatomy for educational and training purposes as well as at events held for the edification of the general public.

Initial approaches to virtual anatomy emerged in the 1990s. A key development in this context was the Visible Human Project of the National Library of Medicine (NLM). This project derived detailed data for use in human anatomical visualization from cross-sections of complete human bodies. To accomplish this, the bodies of two human donors were frozen and cut into thin slices, which were then photographed and digitized $[11,12]$. The NLM made the data available in a form that is suitable for depiction on computers, data processing and interaction [13]. Another significant step was the development of program systems that could use these data for the production and visualization of three-dimensional digital models of the human body-for example, Voxel-Man [14]. With the advent of Voxel-Man, it was already possible to utilize radiological cross-section data derived from CT and MR examinations for the three-dimensional depiction of human anatomy. Following the Visible Human Project, two more data sets of the human body were produced and made publically available: the Chinese Visible Human Project $[15,16]$ and the Visible Korean Human [17]. A relatively new approach in the field of virtual anatomy is the use of volume rendering programs for three-dimensional color-coded depictions of the anatomy of living persons generated from cross-section data derived from CT and MR examinations [18].

\section{THE SETTING}

The Ars Electronica Center (AEC) in Linz, Austria describes itself as the Museum of the Future. A major part of its mission is to showcase multifarious amalgamations across the artistic, scientific and technological spectrums, and to nurture their ongoing development. The AEC also offers its visitors one-of-a-kind infrastructure including a venue for screening high-definition graphics that accommodates up to 150 persons (Figure 1).

It offers the possibility of both 16-by-9-meter wall projections and 16-by-9-meter floor projections. To achieve this, four projectors serve the wall and four serve the floor-thus, a total of eight projectors are used.

The projectors were constructed from Christie Boxer 4K30s. Each one puts out 30,000 ANSI lumens. Four parallel signal feeds are necessary for each projector, since the huge quantities of image data generated cannot, at present, be transported via a single signal channel. The image is generated in concert-4096 × 2160 pixels, each one computed 120 times per second and transported via four separate cables to each of the four projectors. This means that over 4.2 billion pixels per second have to be transported. Furthermore, these figures apply to each projection surface; thus, for Deep Space's dual projection 


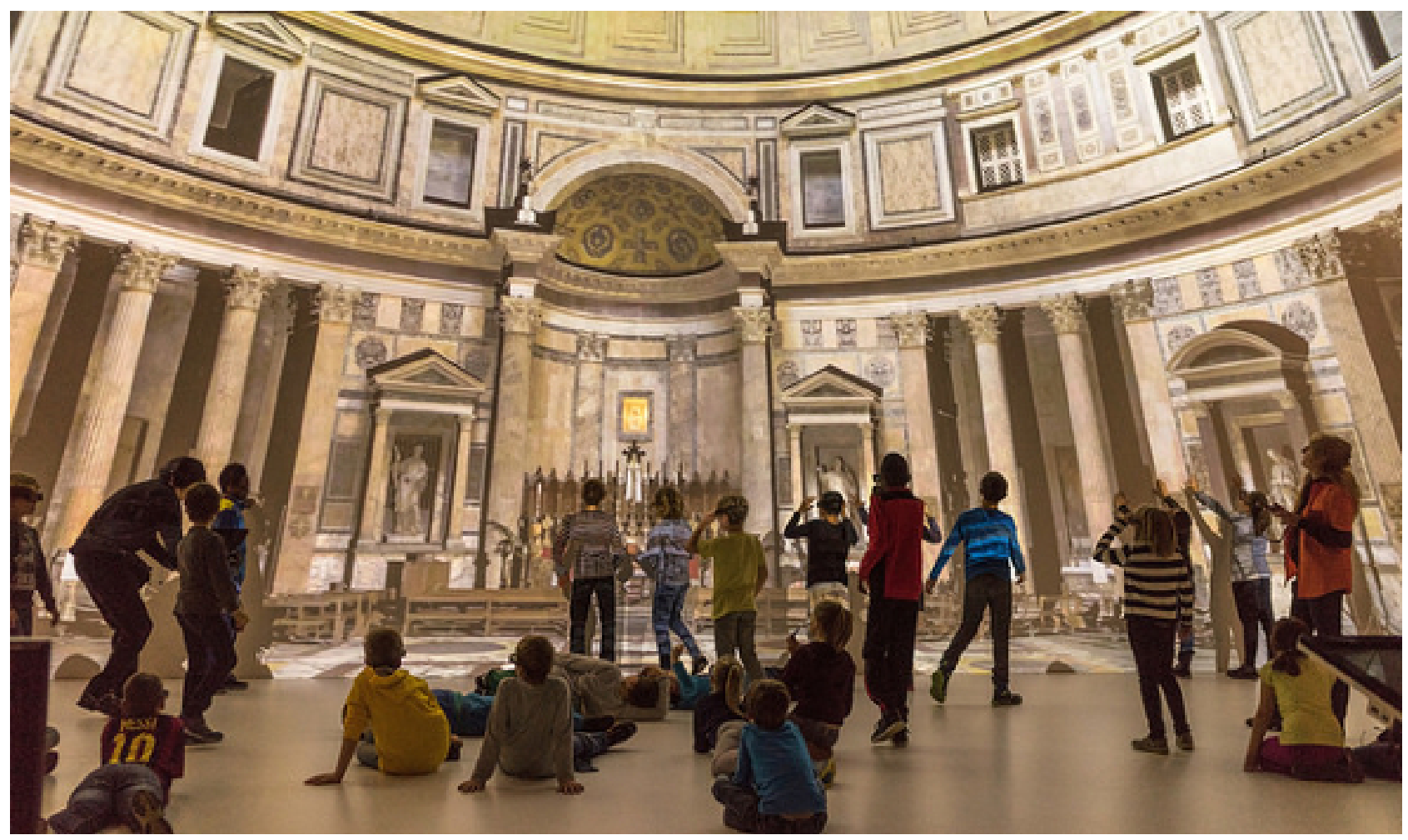

Figure 1. Ars Electronica Center, Deep Space 8K: This virtual visit to the Pantheon in Rome is made possible by a BBC production that was optimized for Deep Space $8 \mathrm{~K}$ in cooperation with ScanLAB Projects. To accomplish this, high-definition color scans were used to capture and depict 3-D point clouds of streets, buildings and hidden subterranean spaces in brillant crystal clarity.

surfaces (front wall and floor), the bottom line is twofold. The systems are synchronized with one another and achieve a transport rate of slightly over 23 gigabytes/second. By way of comparison-almost the entire contents of a BlueRay disc are transported per second. To run Cinematic Rendering, this flow of data is computed in real time, which calls for processing output at the very limits of technical feasibility. This is achieved by a quartet of NVIDIA Quadro M6000 graphics cards for each projector. In order for a single motherboard to operate these cards, high-performance processors manufactured by XI-MACHINES are employed.

This facility makes laser tracking, 3-D films and interactive 3-D real-time graphics in high-resolution $8 \mathrm{~K}$ available to the general public. By means of 3-D shutter glasses, visitors enjoy an impressive three-dimensional experience (Figure 2).

Since January 2014, this facility has also served as an open university offering anatomy lectures open to the general public. Until September 2015, we had used a stereoscopy-capable volume rendering program developed especially for this purpose by a member of the Ars Electronica Futurelab's staff (Figure 3). This made it possible to three-dimensionally depict the anatomy of a living person in real time on the basis of CT and MR examinations [10].

In summer 2015, a stereoscopy-capable prototype of Cinematic Rendering was installed in Deep Space. The installation proceeded smoothly, and the program could immediately be integrated into the museum's everyday operations to three-dimensionally depict CT and MR data sets. Since September 2015, we have exclusively used Cinematic Rendering instead of volume rendering to generate three-dimensional depictions of human anatomy from CT and MR data sets, since the resulting quality of the visualization is considerably more photo-realistic than what had previously been possible with volume rendering methods (Figure 4). 


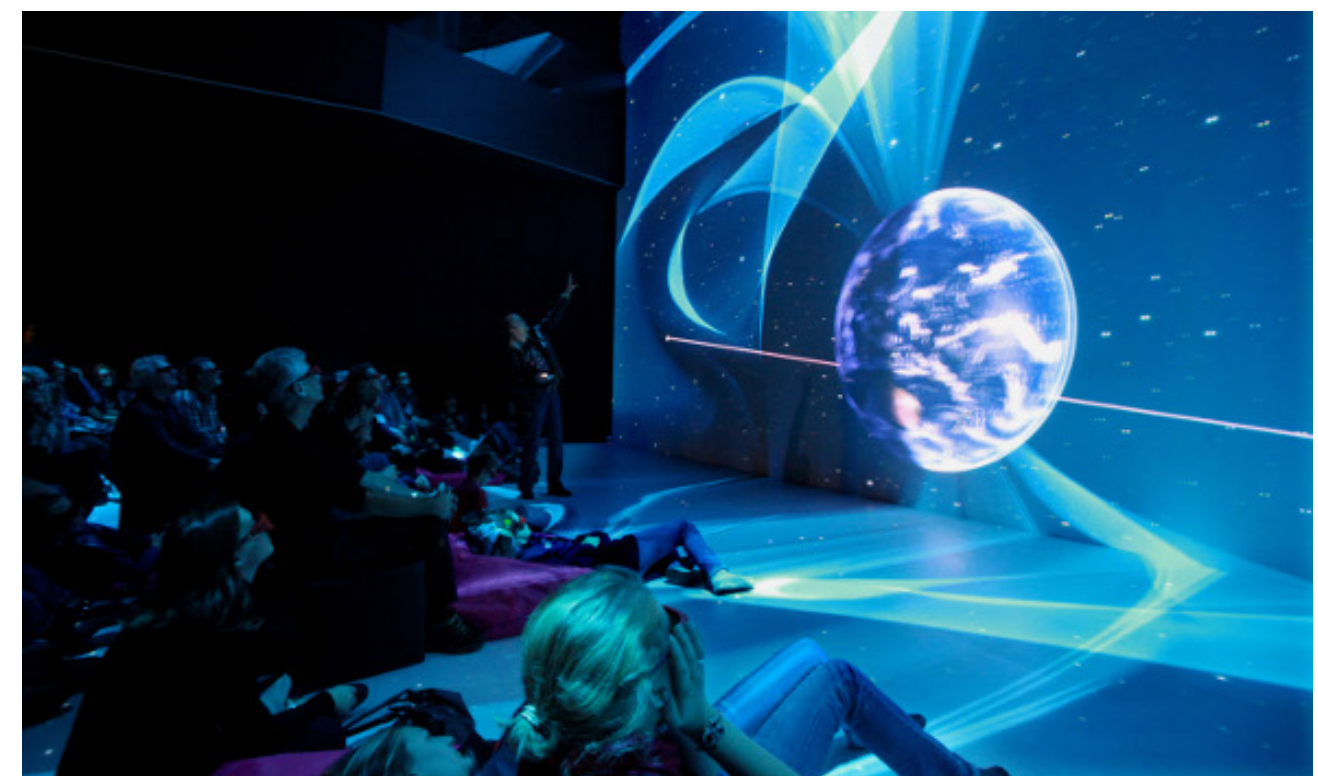

Figure 2. Ars Electronica Center, Deep Space 8K. A fascinating journey through outer space in 3-D-from Earth to the limits of the universe-is visualized by Uniview software developed by a Swedish firm, SCISS. This atlas of the cosmos-true to scale and based on the current state of scientific knowledge-was adapted especially for Deep Space in $8 \mathrm{~K}$ resolution and for wall \& floor projection.

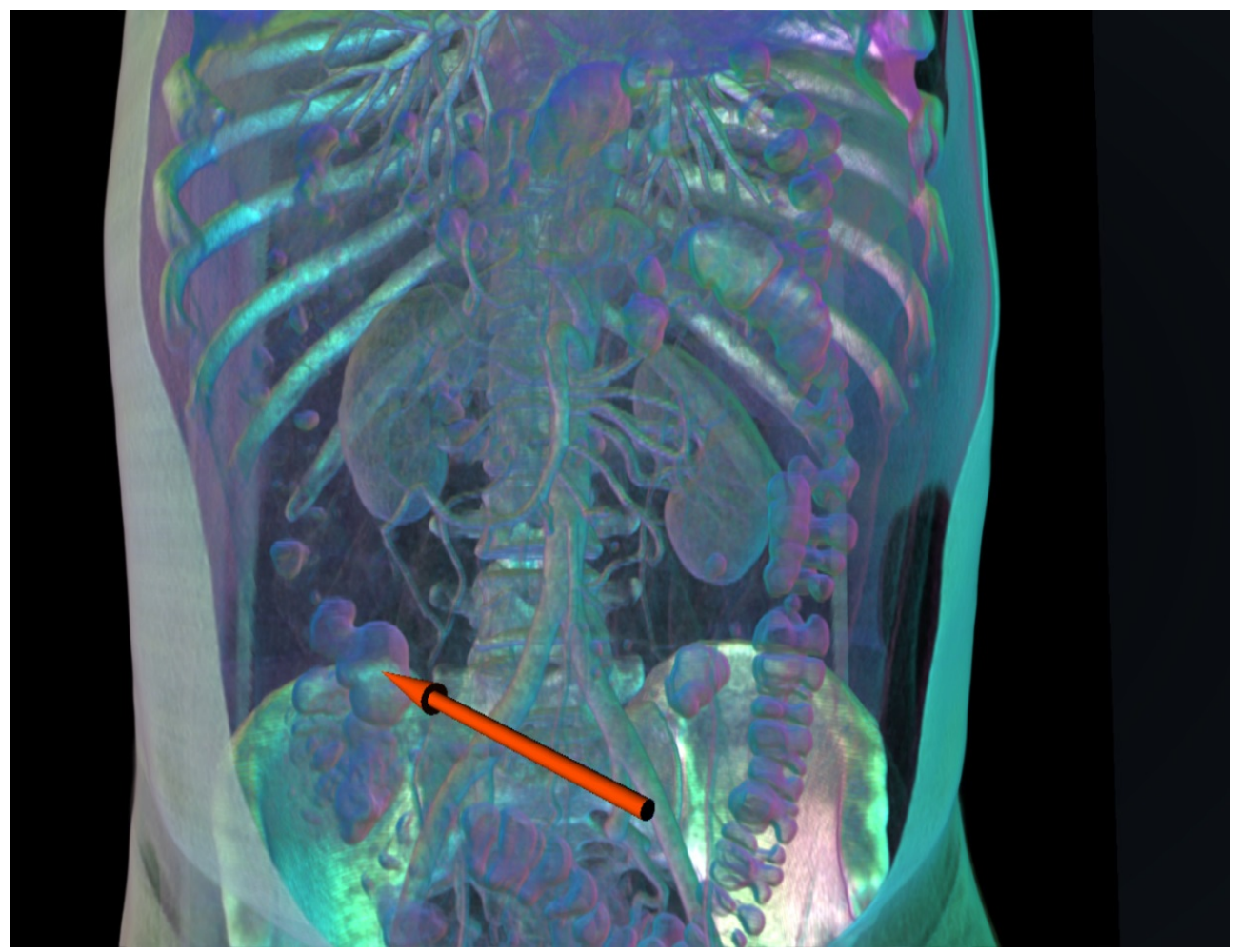

Figure 3. 3-D depiction of a contrast-enhanced abdomen CT data set displayed on Deep Space's 16by-9-meter projection surface through the use of the stereoscopy-capable volume rendering program developed especially for this purpose in house at the Ars Electronica FutureLab. 
The Cinematic Rendering prototype is operated by a commercially available game controller (Figure 5), whereby each button is assigned multiple functions. These make a wide assortment of screening options available-e.g. zoom, shift, window leveling, cut planes in various levels, changing the background onto which the data set is projected, and modifying the brightness.

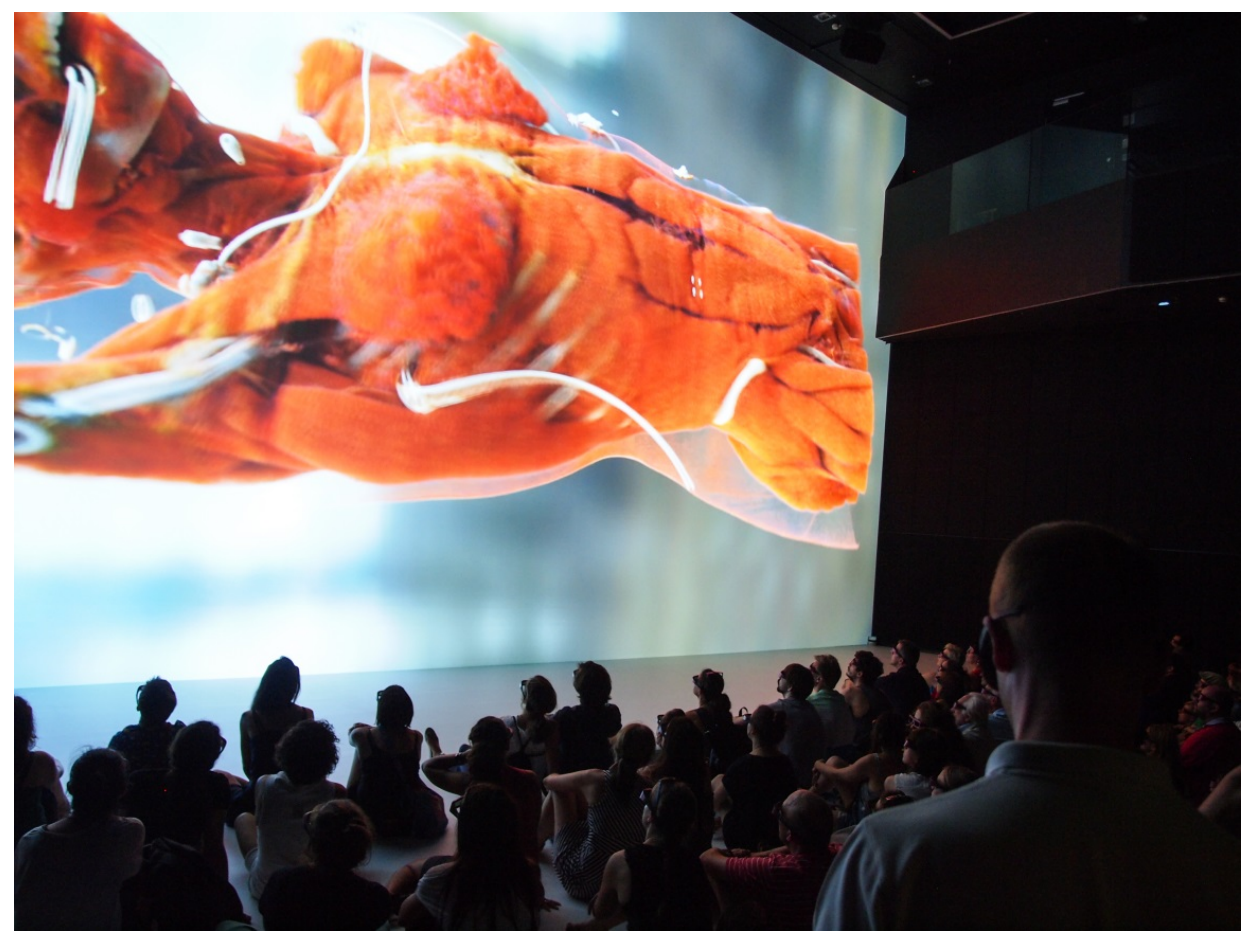

Figure 4. 3-D depiction of a contrast-enhanced whole body CT data set produced by the Cinematic Rendering program prototype installed in Deep Space.

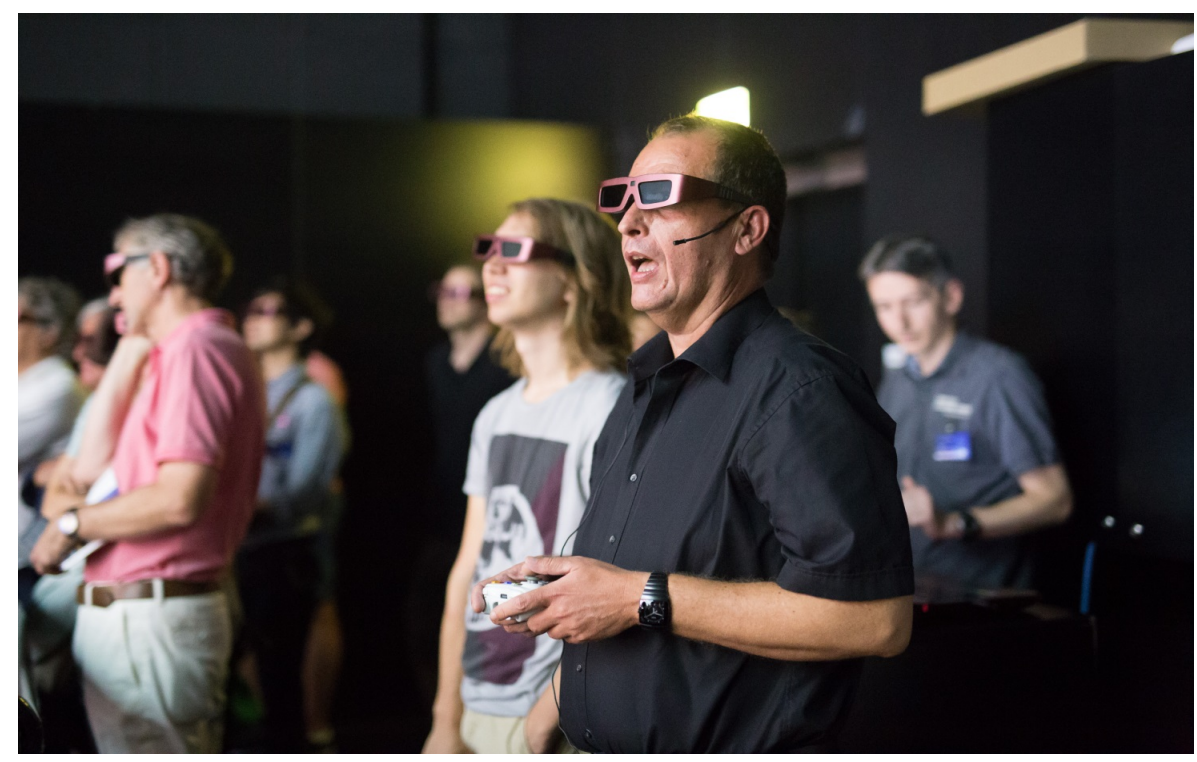

Figure 5. A game controller enables wireless operation of the Cinematic Rendering prototype. By assigning multiple functions to each of the controller's buttons, a wide array of software functions can be launched. 


\section{DISCUSSION}

Interactive anatomy programs for computer-graphics-generated models of human anatomy that are very well-suited to anatomy instruction are currently available on the market, e.g. Zygote Body [19]. This is referred to as "virtual anatomy" in contradistinction to the conventional study of anatomy entailing cadavers and anatomy textbooks [20]. Moreover, x-ray, angiography, CT and MR images have also been used in anatomy instruction for several years now.

Radiological procedures such as x-ray imaging and, above all, CT and MR data are superbly suited to the visualization and teaching of human anatomy in conjunction with "virtual anatomy" as a supplement to conventional cadaver anatomy. Due to the huge technical progress that has been made in the field of imaging (particularly CT and MR) as well as the post-processing of the data generated thereby, this new area within virtual anatomy as well as the entire field of virtual anatomy itself will significantly gain importance in the near future. The implementation of stereoscopic Cinematic Rendering in a large high-resolution projection space yields unprecedented new possibilities in anatomy instruction.

Cinematic Rendering [21] is a software and algorithm developed by Siemens Healthcare that simulates the interaction of visible photons with the scanned patient anatomy. The software computes volumetric light transport and is based on a volumetric Monte Carlo path tracing algorithm [21, 22]. The light transport simulation generates photo-realistic and hyper-realistic images by tracing between hundreds to thousands of photons paths per pixel through the anatomy using a stochastic process. Such paths are the result of light being scattered multiple times before it reaches the virtual light sensor. The light originates from high-dynamic range (HDR) lighting environments, which can either be captured photographically (image-based lighting) or generated synthetically. Photographically captured lighting leads to a very natural appearance of the data when compared to images created using the traditional ray casting method. Tone mapping is used to map the resulting high-dynamic range visualizations to the limited dynamic range of an output device, such as the projectors used in Deep Space 8k. The natural lighting in combination with the accurate simulation of photon scattering and absorption leads to photorealistic images that resemble many shading effects that can be observed in nature, such as soft shadows, ambient occlusion, volumetric scattering and subsurface photon interaction. By modelling a virtual camera with variable aperture, focal length and exposure, effects such as depth-of-field and motion blur can be produced. Motion blur allows animations generated using our key frame animation engine to be smoother during fast camera movements while, similar to photography, depth-of-field effects allow to focus the attention of a viewer on a particular anatomical structures.

Path tracing methods are inherently computationally expensive, since hundreds to thousands of light paths must be computed for each pixel to generate a smooth image result. Consequently, the computation of images in real-time at the enormous resolution of Deep Space 8k in stereo requires a combination of high-end professional graphics accelerators (GPUs) and optimized algorithms. A total of eight high-end NVIDIA Quadro M6000/P6000 graphics accelerators drive the projection in Deep Space. They run the highly optimized Monte Carlo path tracing algorithm which identifies the most important light paths that have the highest contribution to the final image result. Stereoscopic visualization at $8 \mathrm{k}$ resolution is implemented using OpenGL quad buffering and NVIDIA Mosaic ${ }^{\mathrm{TM}}$ technology.

Since the implementation in summer 2015, this projection space has hosted more than 100 events having to do with virtual anatomy. These events have included both anatomy lectures conceived for and open to the general public as well as presentations especially for interns, residents and specialists in various disciplines including neurosurgery, general surgery, diabetology, gastroenterology and emporiatrics (travel medicine). Total attendance at these events was $14,000+$.

Furthermore, since autumn 2016, all 24 classroom sessions of the Introduction to Anatomy course taken by students enrolled in the Physiotherapy and Radiology Technicians programs at the local University of Applied Sciences for Health Professions have been held in Deep Space at the Ars Electronica Center and employed Cinematic Rendering for 3-D visualization of human anatomy on the basis of CT and MR data sets (Figure 6). The school leases Deep Space from the Ars Electronica Center to be able to hold these 


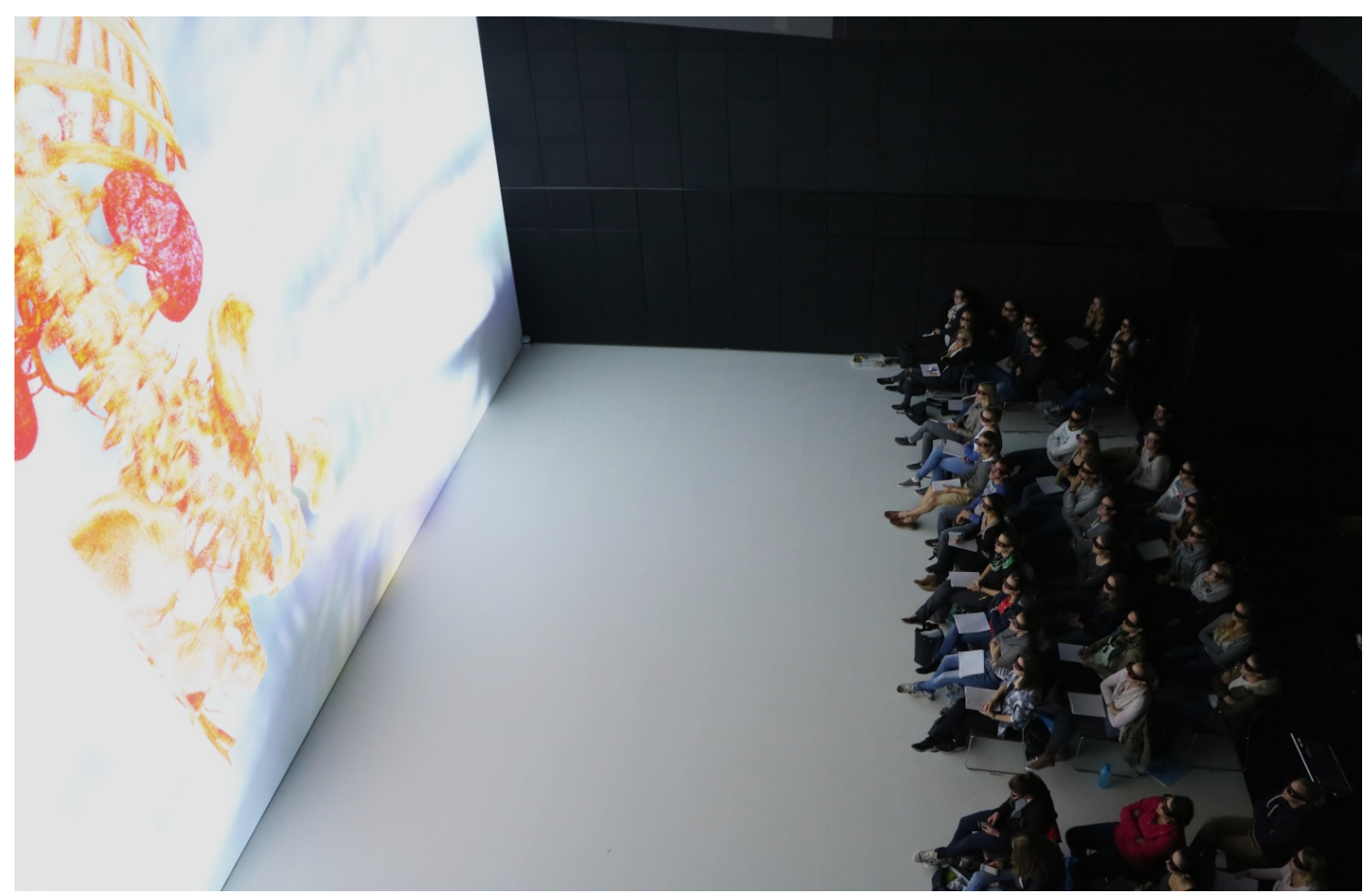

Figure 6. Since autumn 2016, the Introduction to Anatomy course (24 classroom sessions) taken by students in the Physiotherapy and Radiology Technicians programs at the local University of Applied Sciences for Health Professions has routinely been held in the Ars Electronica Center's Deep Space, where the stereoscopy-capable prototype of Cinematic Rendering is utilized.

courses there.

Not only the implementation of the stereoscopy-capable Cinematic Rendering prototype proceeded without a glitch; the installation has also proven to be very robust in everyday operations since then. Not a single crash or other technical problem occurred at any of the 100+ events at which the software was used.

This new approach-a "Dissecting Theater of the Future" suitable for a broad spectrum of usages ranging from open university-type adult continuing education presentations to courses for medical and health professionals-has thus proven itself to be not only feasible but also reliable in everyday operation.

Utilizing this new approach to complement previous virtual anatomy applications yields several advantages:

- The anatomy of living human beings is used; thus, blood vessels in particular are depicted very vividly since blood is flowing through them.

- The new Cinematic Rendering 3-D rendering technique used in combination with $8 \mathrm{~K}$ projection technology produces excellent three-dimensional image quality (Figure 4) in real time.

- Stereoscopic depiction via the use of 3-D shutter glasses enables viewers to see a very realistic threedimensional image.

- Due to the huge size of the projection surface $(16 \times 9 \mathrm{~m})$, even tiny anatomical structures can be clearly depicted and are thus easy for viewers to recognize.

- The size of the viewing space makes it possible to accommodate an audience of 150; thus, in addition to training classes and seminars, this technology can also be used in conjunction with lecture courses.

\section{CONCLUSIONS}

Virtual anatomy will assume increasing importance in the future as a supplement to the conventional teaching of anatomy using cadavers and textbooks. Moreover, this substantially enhances the quality of 
training provided in health professions in which students normally do not have access to the study of cadavers - i.e. all professions other than physician: nurse, physiotherapist, speech pathologist, paramedic, et al.

The procedure described here was entailed using software for photorealistic 3-D post-processing of medical imaging data from CT and MR examinations and screening the resulting images in a large stereoscopy-capable high-definition projection space. This yields further progress in the field of virtual anatomy. Such a venue could be a setting for interactive speeches and courses such as lectures, seminars and training provided in conjunction with internships.

\section{REFERENCES}

1. Fellner, F.A. (2016) Introducing Cinematic Rendering: A Novel Technique for Post-Processing Medical Imaging Data. Journal of Biomedical Science and Engineering, 9, 170-175. https://doi.org/10.4236/jbise.2016.93013

2. Comaniciu, D., Engel, K., Georgescu, B. and Mansi, T. (2016) Shaping the Future through Innovations: From Medical Imaging to Precision Medicine. Medical Image Analysis, 33, 19-26.

3. Dappa, E., Higashigaito, K., Fornaro, J., Leschka, S., Wildemuth, S. and Alkadhi, H. (2016) Cinematic Rendering-An Alternative to Volume Rendering for 3D Computed Tomography Imaging. Insights Imaging, 7, 849856. https://doi.org/10.1007/s13244-016-0518-1

4. Ebert, L.C., Schweitzer, W., Gascho, D., Ruder, T.D., Flach, P.M., Thali, M.J. and Ampanozi, G. (2017) Forensic 3D Visualization of CT Data Using Cinematic Rolume Rendering. A Preliminary Study. American Journal of Roentgenology, 208, 233-240. https://doi.org/10.2214/AJR.16.16499

5. Eid, M., De Cecco, C.N., Nance, J.W., Caruso, D., Albrecht, M.H., Spandorfer, A.J., De Santis, D., Varga-Szemes, A. and Schoepf, U.J. (2017) Cinematic Rendering in CT: A Novel, Lifelike 3D Visualization Technique. American Journal of Roentgenology, 1-10. https://doi.org/10.2214/AJR.17.17850

6. Johnson, P.T., Schneider, R., Lugo-Fagundo, C., Johnson, M.B. and Fishman, E.K. (2017) MDCT Angiography with 3D Rendering: A Novel Cinematic Rendering Algorithm for Enhanced Anatomic Detail. American Journal of Roentgenology, 1-4. https://doi.org/10.2214/AJR.17.17903

7. Fellner, F.A. and Behawy, M. (2017) Cinematic and Volume Rendering of a Scaphoid Fracture. Glob Imaging Insights, 2, 1-2. https://doi.org/10.15761/GII.1000111

8. Akbari, K., Fellner, C.M. and Fellner, F.A. (2017) Rare Case of an Aneurysmal Bone Cyst of the Skull. Glob Imaging Insights, 2. https://doi.org/10.15761/GII.1000116

9. Fellner, F.A. (2016) "Cinematic Rendering” of an Egyptian Fish Mummy with a Fractured Spinal Column. Glob Imaging Insights, 2. https://doi.org/10.15761/GII.1000107

10. Fellner, F.A., Berger, F., Fellner, C., Kremer, C., Hörtner, H. and Stocker, G. (2016) Stereoscopic Volume Rendering of Medical Imaging Data for the General Public. Journal of Health and Medical Informatics, 7, 213. https://doi.org/10.4172/2157-7420.1000213

11. Ackerman, J.M., Spitzer, V.M., Scherznger, A.L. and Whitlock, D.G. (1995) The Visible Human Data Set: An Image Resource for Anatomical Visualization. Medinfo, 8, 1195-1198.

12. Spitzer, V., Ackerman, M.J., Scherzinger, A.L. and Whitlock, D. (1996) The Visible Human Male: A Technical Report. Journal of the American Medical Informatics Association, 3, 118-130.

https://doi.org/10.1136/jamia.1996.96236280

13. Spitzer, V.M. and Scherzinger, A.L. (2006) Virtual Anatomy: An Anatomist's Playground. Clinical Anatomy, 19, 192-203. https://doi.org/10.1002/ca.20330

14. Schubert, R., Schiemann, T., Tiede, U. and Höhne, K.H. (1997) Applications and Perspectives in Anatomical 3-Dimensional Modelling of the Visible Human with VOXEL-MAN. Acta Anatomica, 160, 123-131. 


\section{https://doi.org/10.1159/000148004}

15. Zhang, S.X., Heng, P.A., Liu, Z.J., Tan, L.W., Qiu, M.G., Li, Q.Y., Liao, R.X., Li, K., Cui, G.Y., Guo, Y.L., Yang, X.P., Liu, G.J., Shan, J.L., Liu, J.J., Zhang, W.G., Chen, X.H., Chen, J.H., Wang, J., Chen, W., Lu, M., You, J., Pang, X.L., Xiao, H. and Xie, Y.M. (2003) Creation of the Chinese Visible Human Data Set. Anatomical Record. Part B, New Anatomist, 275, 190-195. https://doi.org/10.1002/ar.b.10035

16. Zhang, S.X., Heng, P.A., Liu, Z.J., Tan, L.W., Qiu, M.G., Li, Q.Y., Liao, R.X., Li, K., Cui, G.Y., Guo, Y.L., Yang, X.P., Liu, G.J., Shan, J.L., Liu, J.J., Zhang, W.G., Chen, X.H., Chen, J.H., Wang, J., Chen, W., Lu, M., You, J., Pang, X.L., Xiao, H., Xie, Y.M. and Cheng, J.C. (2004) The Chinese Visible Human (CVH) Datasets Incorporate Technical and Imaging Advances on Earlier Digital Humans. Journal of Anatomy, 204, 165-173. https://doi.org/10.1111/j.0021-8782.2004.00274.x

17. Park, J.S., Chung, M.S., Hwang, S.B., Lee, Y.S., Har, D.H. and Park, H.S. (2005) Visible Korean Human: Improved Serially Sectioned Images of the Entire Body. IEEE Transactions on Medical Imaging, 24, 352-360. https://doi.org/10.1109/TMI.2004.842454

18. Silverstein, J.C., Parsad, N.M. and Tsirline, V. (2008) Automatic Perceptual Color Map Generation for Realistic Volume Visualization. Journal of Biomedical Informatics, 41, 927-935.

19. Kelc, R. (2012) Zygote Body: A New Interactive 3-Dimensional Didactical Tool for Teaching Anatomy. Webmed Central Anatomy, 3, WMC002903. https://doi.org/10.9754/journal.wmc.2012.002903

20. Pommert, A., Höhne, K.H., Burmester, E., Gehmann, S., Leuwer, R., Petersik, A., Pflesser, B. and Tiede, U. (2006) Computer-Based Anatomy a Prerequisite for Computer-Assisted Radiology and Surgery. Academic Radiology, 13, 104-112.

21. Rezk-Salama, C. (2007) GPU-Based Monte-Carlo Volume Raycasting. Proceedings of the Pacific Conference on Computer Graphics and Applications, Maui, 29 October-2 November 2007, 411-414. https://doi.org/10.1109/PG.2007.27

22. Kroes, T., Post, F.H. and Botha, C.P. (2012) Exposure Render: An Interactive Photo-Realistic Volume Rendering Framework. PLoS ONE, 7, e38586.

\section{Scientific Research Publishing}

\section{Submit or recommend next manuscript to SCIRP and we will provide best service for you:}

Accepting pre-submission inquiries through Email, Facebook, LinkedIn, Twitter, etc.

A wide selection of journals (inclusive of 9 subjects, more than 200 journals)

Providing 24-hour high-quality service

User-friendly online submission system

Fair and swift peer-review system

Efficient typesetting and proofreading procedure

Display of the result of downloads and visits, as well as the number of cited articles

Maximum dissemination of your research work

Submit your manuscript at: http://papersubmission.scirp.org/

Or contact jbise@scirp.org 